\title{
Sentimentos de Enfermeiras no Cuidado de Pessoas com Feridas Neoplásicas
}

\section{Nurses' Feelings About Caring for People with Neoplastic Wounds}

\author{
Débora Thaise Freires de Brito $^{1}$ \\ Glenda Agra ${ }^{2}$ \\ Maria Vitória de Souza Medeiros ${ }^{3}$ \\ Irys Karla Cosmo Pereira ${ }^{4}$ \\ Elton de Lima Macedo ${ }^{5}$ \\ Fábia Letícia Martins de Andrade ${ }^{6}$
}

\footnotetext{
${ }^{1}$ Enfermeira. Universidade Federal de Campina Grande/UFCG, campus Cuité. Residente pelo Programa de Residência Multiprofissional em Saúde da Família e Comunidade. João Pessoa - Paraíba, Brasil. E-mail: deborathaise_@hotmail.com. Autor correspondente

${ }^{2}$ Enfermeira. Doutoranda pelo Programa de Pós-Graduação em Enfermagem da Universidade Federal da Paraíba/UFPB. Docente do Curso de Graduação em Enfermagem da Universidade Federal de Campina Grande/UFCG, campus Cuité. João Pessoa - Paraíba, Brasil. E-mail: gledaagra@outlook.com.

${ }^{3}$ Enfermeira. Universidade Federal de Campina Grande/UFCG, campus Cuité. Cuité - Paraíba, Brasil. E-mail: vitória_unco@yahoo.com.br.

${ }^{4}$ Enfermeira. Universidade Federal de Campina Grande/UFCG, campus Cuité, Cuité - Paraíba, Brasil. E-mail: iryscosmopereira@hotmail.com.

${ }^{5}$ Enfermeiro. Universidade Federal de Campina Grande/UFCG, campus Cuité. Residente de Enfermagem em Cancerologia no Hospital Universitário Oswaldo Cruz/HUOC-UPE. Recife - Pernambuco, Brasil. E-mail: eltonneltonIm@hotmail.com.
}

${ }^{6}$ Acadêmica de Enfermagem. Universidade Federal de Campina Grande/UFCG, campus Cuité. Cuité - Paraíba, Brasil. E-mail: lethyciaandrade@hotmail.com. 


\section{Resumo}

O objetivo é compreender os sentimentos de enfermeiras no cuidado de pessoas com feridas neoplásicas durante a realização do curativo. Trata-se de um estudo exploratório, de natureza qualitativa, realizado com 20 enfermeiras assistenciais de um hospital filantrópico da Paraíba que presta cuidados a pacientes com doença oncológica avançada. Os dados foram coletados no período de abril a junho de 2016, por meio de entrevistas norteadas por um roteiro semiestruturado, após aprovação do Comitê de Ética em Pesquisa do Hospital Universitário Alcides Carneiro sob parecer n.o 1.320.367 e analisadas por meio da Técnica de Análise do Conteúdo de Bardin. Os discursos apontaram sentimentos positivos e negativos, percebidos durante a realização dos curativos, onde o sentimento tristeza obteve o maior percentual de respostas. Evidenciou-se que as enfermeiras desenvolvem habilidades empáticas diante do sofrimento do paciente, promovendo ações de solicitude com vistas ao conforto físico e psíquico do mesmo.

Palavras-chave: Oncologia; Enfermagem Oncológica; Neoplasias Cutâneas.

\section{Abstract}

The aim is to understand the nurses' feelings in the care of people with neoplastic wounds during the dressing. This is an exploratory qualitative study carried out with 20 nursing assistants from a philanthropic hospital in Paraíba that provides care to patients with advanced cancer disease. The data were collected from April to June 2016, through interviews guided by a semi-structured script, after approval of the Research Ethics Committee of the Alcides Carneiro University Hospital under opinion No. 1,320,367 and analyzed by means of the Technique of Bardin Content Analysis. The speeches pointed to positive and negative feelings, perceived during the dressings accomplishment, where the sad feeling obtained the highest percentage of responses. It was evidenced that the nurses develop empathic abilities in the face of the patient's suffering, promoting solicitude actions with a view to the physical and psychic comfort of the same.

Keywords: Oncology; Oncological Nursing; Cutaneous Neoplasms. 


\section{Introdução}

A incidência do câncer vem aumentando nas últimas décadas e, na atualidade, a doença se caracteriza como um importante problema de saúde pública no Brasil e no mundo, constituindose como a segunda causa de morte brasileira com 190 mil óbitos por ano(1)

No Brasil, a estimativa para o biênio 2016/2017 aponta a ocorrência de aproximadamente 600 mil novos casos de câncer, incluindo os casos de pele não melanoma, o que reforça a magnitude do problema do câncer no país. Em relação ao número de casos novos de câncer, por estado, o câncer de pele do tipo não melanoma (182 mil casos novos) será o mais incidente na população brasileira, seguido pelos tumores de próstata (61 mil), mama feminina (57 mil), cólon e reto (34 mil), traqueia, brônquio e pulmão (28 mil), estômago (20 mil), colo do útero (16 mil), cavidade oral (15 mil), entre outros. Para estes mesmos anos, na região Nordeste, estima-se que ocorram 47.520 casos novos de neoplasia em homens e 51.540 em mulheres ${ }^{(1)}$.

As feridas neoplásicas são formadas pela infiltração das células malignas do tumor nas estruturas da pele que levam, consequentemente, à quebra da sua integridade, com posterior formação de uma ferida evolutivamente exofítica, decorrente da proliferação celular descontrolada que o processo de oncogênese provoca. As mesmas também são denominadas de lesões neoplásicas, oncológicas, malignas, tumorais ou fungóides, quando apresentam aspecto de cogumelo ou couve-flor; e sua prevalência, independente da localização anatômica, não é bem documentada, mas se estima a partir de estudos internacionais, que 5 a $10 \%$ das pessoas com câncer as desenvolvem ${ }^{(2-3)}$.

As feridas neoplásicas que acometem a pele constituem mais um agravo na vida da pessoa com doença oncológica, porque, progressivamente, desfiguram o corpo e tornamse friáveis, dolorosas, exsudativas e liberam odor fétido. A deformidade corporal causada por essas feridas, pode provocar no paciente distúrbio da autoimagem e desgaste psicológico, sensação de desamparo, humilhação e isolamento social|(3-4-5).
O tratamento e cuidado dessas lesões é um assunto complexo, porque exige avaliação de etiologia oncológica, das características da ferida, do estado físico e emocional do paciente e do estadiamento da ferida. É nesse contexto, que o enfermeiro oferece o cuidado mais genuíno, que transcende além das necessidades básicas, onde o enfermeiro é capaz de acessar aspectos emocionais e subjetivos, de forma a alcançar a transpessoalidade, por meio da comunicação e empatia e, com isso, desenvolver e manter a harmonia e confiança necessárias para este processo e, além de desenvolver competências e habilidades que thes permite implementar ações específicas às necessidades identificadas ${ }^{(6)}$.

Diante disso, faz-se necessário compreender o processo do cuidado entre enfermeiro e paciente com feridas neoplásicas, uma vez que o enfermeiro é o profissional integrante da equipe multi e interdisciplinar que está em maior contato com o paciente. Diante disso, realizou-se uma busca nas bases de dados indexadas, utilizando os descritores "feridas oncológicas", "feridas tumorais", "feridas neoplásicas", "feridas malignas", "vivências", "sentimentos", "cuidado" e "enfermeiros" com os operadores booleanos "OR" e "AND" e verificou-se uma escassez de artigos publicados que vislumbrassem a temática em bases de dados cientificamente confiáveis.

Nessa perspectiva e na intenção de aprofundar o conhecimento acerca dessa temática, emergiu a seguinte questão norteadora da pesquisa: Quais os sentimentos de enfermeiras frente a pacientes com feridas neoplásicas?

Desse modo, o objetivo deste estudo é compreender os sentimentos de enfermeiras no cuidado de pessoas com feridas neoplásicas durante a realização do curativo.

\section{Método}

Trata-se de uma pesquisa exploratória, de natureza qualitativa. O cenário da investigação foram unidades de internação de um hospital filantrópico, localizado na cidade de Campina Grande (PB), considerado referência no estado da Paraíba. 
A instituição lócus da pesquisa apresenta um quantitativo de 26 enfermeiros na sua totalidade; destes, 23 são mulheres e três são homens. Todavia, somente mulheres aceitaram participar da pesquisa, por isso, os pesquisadores decidiram uniformizar o título. As participantes da pesquisa foram 20 enfermeiras assistenciais da instituição, que prestam cuidados direcionados ao paciente com doença oncológica que apresenta ferida neoplásica, selecionadas mediante os seguintes critérios: que o profissional atuasse há pelo menos um ano na referida unidade, estivesse em atividade laboral durante o período de coleta de dados e disponibilidade e interesse em participar da pesquisa, confirmando sua concordância com a assinatura do Termo de Consentimento Livre e Esclarecido (TCLE). Foram excluídos aqueles que estivessem afastados (férias, licenças, capacitação).

A coleta do material empírico ocorreu durante o período de abril a junho de 2016 e somente foi iniciada após a aprovação do projeto de pesquisa pelo Comitê de Ética em Pesquisa do Hospital Universitário Alcides Carneiro da Universidade Federal de Campina Grande (HUAC/UFCG), sob o CAAE 50354215.9.0000.5182. Dessa forma, ressalte-se que o estudo foi realizado considerando-se as observâncias éticas contempladas na Resolução n. 466/2012 do Conselho Nacional de Saúde, no que concerne às normas e às diretrizes regulamentadoras da pesquisa com seres humanos.

Para a obtenção do material empírico, foi utilizado um roteiro com questões pertinentes ao objetivo proposto. As entrevistas foram realizadas em um local específico do hospital, sem interrupções, gravadas mediante autorização e tiveram duração de aproximadamente trinta minutos cada. Convém mencionar que, para manter o anonimato das enfermeiras do estudo, os depoimentos oriundos do referido formulário foram identificados pela sigla "Enf.", seguido de números de um a vinte. Exemplo: a primeira enfermeira entrevistada foi codificada da seguinte maneira: "Enf.1"; a segunda profissional, "Enf.2" e assim por diante.

Logo após o término das entrevistas, as falas foram transcritas integralmente e foram submetidas em conformidade com a Técnica de Análise do Conteúdo de Bardin ${ }^{(7)}$. A análise e interpretação dos dados empíricos foram divididas em três etapas: a primeira foi composta pela préanálise, que consistiu na leitura flutuante do conjunto das informações, na constituição do corpus e na formulação de hipóteses e objetivos; a segunda etapa consistiu na exploração do material, instante em que as pesquisadoras organizaram os dados a partir das categorias, reduzindo o texto às expressões significativas e a terceira etapa englobou o tratamento dos resultados obtidos e a interpretação, na qual realizaram inferências e interpretações, correlacionando-as com a literatura pertinente.

\section{Resultados}

Participaram deste estudo 20 enfermeiras, com idade entre 24 e 60 anos, sendo 14 casadas, 5 solteiras e 1 viúva. As características das participantes da pesquisa que atuavam na instituição lócus da pesquisa revelaram uma diversidade de 1 a 39 anos em relação ao tempo de formação, de 6 meses a 28 anos no que se refere ao tempo de experiência profissional e 2 meses a 10 anos no que se concerne ao tempo de experiência na área de Oncologia.

A fim de se compreender os sentimentos das enfermeiras durante o cuidado prestado ao paciente com feridas neoplásicas no decorrer da realização do curativo, solicitou-se que as mesmas respondessem à seguinte questão: "Fale-me sobre os sentimentos vivenciados por você durante a realização do curativo". Os discursos estão expostos logo abaixo, no Quadro 1. 
Quadro 1. Distribuição das categorias, frequências e falas das enfermeiras no que se refere à questão "Faleme sobre os sentimentos vivenciados por você durante a realização de um curativo". Campina Grande, PB,

Brasil, 2016.

\begin{tabular}{|c|c|c|}
\hline Categorias & $F(n=20)$ & Falas \\
\hline Tristeza & 07 & $\begin{array}{l}\text { Tem momentos que a gente segura o choro[...] às vezes, o paciente que a gente } \\
\text { tá cuidando há muito tempo vai a óbito. A gente tem que ser muito forte (Enf.1). } \\
\text { Eu sinto realmente uma tristeza em saber a que ponto o ser humano fica com a } \\
\text { ferida neoplásica (Enf.2). } \\
\text { Fico muito triste, preocupada, mas procuro dá o meu melhor, fazer um trabalho } \\
\text { bem feito, proporcionar o bem estar do paciente (Enf.7). } \\
\text { De tristeza[...] eles sofrem muito, dependendo da extensão, profundidade do } \\
\text { ferimento. Por isso, cuido com zelo, atenção, para não sentirem dor (Enf.9). } \\
\text { Tenho sensibilidade. Fico triste (Enf.14). } \\
\text { Sentimento de tristeza, pois o paciente sente medo da morte e também tem o } \\
\text { odor da ferida (Enf.15). } \\
\text { Sentimentos dolorosos (Enf.18). }\end{array}$ \\
\hline Empatia & 05 & $\begin{array}{l}\text { A gente tem que ser muito ético, primeiramente, com o paciente com ferida } \\
\text { neoplásica [...]a maioria dos pacientes tem odores, né? Então, a gente dá } \\
\text { prioridade pra não passar isso pro paciente [...]de que a gente tá sentindo aquele } \\
\text { odor[...] (Enf.1). } \\
\text { A gente sente porque, que queira ou não, nós nos vimos ali naquele sentido, } \\
\text { naquele momento... É uma ferida que requer muitos cuidados. Porque a pessoa } \\
\text { já vem com um diagnóstico negativo e ainda uma ferida provocada pela própria } \\
\text { doença, pelo próprio tumor, isso é muito triste né? (Enf.2). } \\
\text { Durante o tratamento do paciente, tenho o sentimento de me colocar no lugar } \\
\text { do meu paciente, de ver como essa enfermidade está lhe afetando (Enf.3). } \\
\text { Cuidar de um paciente com ferida neoplásica é um pouquinho complicado, } \\
\text { porque além do sofrimento dele, há também o nosso sentimento de tristeza } \\
\text { (Enf.12). } \\
\text { O respeito pelo paciente e a empatia, ou seja, você tem que se colocar o lugar } \\
\text { dele. Tem a questão da humanização também, que é muito importante, que } \\
\text { você tem que se sentir humanizado e humanizar esse momento de realizar um } \\
\text { curativo (Enf.17). }\end{array}$ \\
\hline
\end{tabular}




\begin{tabular}{|c|c|c|}
\hline Compaixão & 04 & $\begin{array}{l}\text { O sentimento seria de compaixão[...] isso me move a tratá-lo da melhor forma } \\
\text { (Enf.4). } \\
\text { A gente sente dó do paciente numa situação daquela (Enf.5). } \\
\text { Sentimento de misericórdia, por se tratar de um ferimento absolutamente } \\
\text { doloroso (Enf.8). } \\
\text { Sentimento de pena. Mas, tento me conter, não demonstrar ao paciente. Se eu } \\
\text { pudesse resolver logo a situação que ele está, resolveria (Enf.13). }\end{array}$ \\
\hline Gratificação & 04 & $\begin{array}{l}\text { Me sinto gratificada em tá podendo ajudar, em oferecer pelo menos conforto } \\
\text { naquela situação tão delicada (Enf.5). } \\
\text { Durante a realização do curativo, sinto realização e prazer em poder estar } \\
\text { cuidando (Enf.16). } \\
\text { Acho que quem cuida tem um sentimento de dever cumprido, de poder oferecer } \\
\text { o seu melhor para buscar uma qualidade de vida melhor do paciente (Enf.19). } \\
\text { Durante a realização do curativo sinto carinho, respeito e ética em relação ao } \\
\text { paciente (Enf.20). }\end{array}$ \\
\hline Apreensão & 01 & $\begin{array}{l}\text { No início, o principal sentimento que marcou quando fui realizar os primeiros } \\
\text { curativos foi o receio, porque a gente vê que boa parte dos pacientes vêm com } \\
\text { um sofrimento maior, porque faz um tempinho que eles já tem aquela ferida, } \\
\text { então a gente tem medo de machucar. Medo de tocar naquela ferida e ela } \\
\text { sangrar e o paciente ficar nervoso, né? (Enf.12). }\end{array}$ \\
\hline Indolência & 01 & $\begin{array}{l}\text { Nós temos que ser humanos com eles, mas se a gente se envolver demais, acaba } \\
\text { não realizando o trabalho da gente com sucesso. Porque aí o emocional vai } \\
\text { atrapalhar, e aí a gente não consegue fazer o curativo (Enf.1). }\end{array}$ \\
\hline
\end{tabular}

Fonte: dados da pesquisa.

A categoria que obteve o maior percentual de respostas, de acordo com o Quadro 1 foi "Tristeza", seguida das categorias "Empatia”, "Gratificação", "Compaixão", "Apreensão" e "Indolência”.

\section{Discussão}

Realizar curativo é uma tarefa reflexiva que não pode ser considerada somente como uma ação técnica, pois envolve uma relação entre duas pessoas: aquela que cuida e aquela que é cuidada. Entretanto, vale salientar que é de extrema importância que o profissional tenha embasamento científico, sendo necessário conhecimento sobre a fisiologia da pele, produtos existentes no mercado, indicações de acordo com o tipo de lesão e conhecimento sobre os produtos que são padronizados no hospital ${ }^{(8)}$.

A equipe de Enfermagem em atenção oncológica, ao realizar o curativo, lida permanentemente com uma diversidade de 
sentimentos que são exacerbadas pelas características da demanda e do ambiente de trabalho, no qual exige do profissional um ato de doação, não somente ao paciente, mas também ao seu familiar/cuidador ${ }^{(9)}$.

Diante disso, para que os cuidados de enfermagem com pacientes com doença oncológica sejam efetivos, o enfermeiro necessita também adquirir habilidade em lidar com os sentimentos dos outros e com as próprias emoções frente ao doente sem possibilidades terapêuticas de cura, e, sobretudo, com uma ferida que não cicatriza ${ }^{(9)}$.

Na categoria "Tristeza", é possível perceber que o sentimento de tristeza ressaltado pelas enfermeiras participantes da pesquisa está relacionado às situações-limite pelas quais o paciente com ferida neoplásica passa, dentre elas: doença sem possibilidades de cura, natureza desfigurante da ferida e o odor fétido exalado pela mesma e a proximidade da morte.

Estudo qualitativo ${ }^{(10)}$ revelou que a aparência física das feridas neoplásicas representa um impacto significativo sobre os enfermeiros, os quais consideram essas lesões a causa maior do sofrimento do paciente, visto que são desfigurantes, invasivas, incuráveis e dolorosas. Além disso, o estudo destacou que o odor fétido foi o maior desafio enfrentado pelos enfermeiros diante da realização de um curativo, contudo, os mesmos não mostraram sinais de aversão durante do procedimento, evitando assim, constrangimento diante do paciente.

Ressalta-se que quanto mais íntimo for o relacionamento do profissional com aqueles de quem cuida, mais propenso estará a experimentar sentimentos de angústia, uma vez que o sofrimento do outro é capaz de mobilizar tristeza, compaixão, piedade e estreitar a aproximação da equipe de enfermagem com pessoas cuja situação de saúde/doença vem acompanhada de características repulsivas $^{(9)}$.

Os profissionais de saúde ao cuidar de pacientes com doença oncológica, principalmente, daqueles com lesões extensas, tornam-se mais frágeis e vulneráveis, pois ao reconhecerem e compreenderem a dor, o sofrimento e a finitude do outro, reconhecem a sua própria dor e finitude. E é a partir desta identificação humana com o paciente, que a enfermagem se reconhece como um ser aberto ao sofrimento, passível de todas as possibilidades que a vida apresenta, sendo a morte a possibilidade mais concreta ${ }^{(11)}$.

Diante desse contexto, cuidar de uma pessoa supõe um trabalho complexo, pois implica a vontade de ajudar a superar o sofrimento, necessitando assim, da presença humana e de um contato íntimo ${ }^{(12)}$. Nessa conjuntura, as enfermeiras participantes da pesquisa se dispuseram a cuidar do paciente com ferida neoplásica, revelando atitudes autênticas, tais como a solidariedade e solicitude.

Sob o ponto de vista psicológico, a arte de cuidar requer o desenvolvimento de empatia. Empatia e simpatia ou compaixão compartilham a mesma raiz etimológica, a saber, o termo pathos, contudo diferem quanto ao sufixo. Nesse sentido, as enfermeiras participantes revelaram a "Empatia" e a "Compaixão" como sentimentos vivenciados no cuidado com pacientes com feridas neoplásicas. Para um melhor entendimento desses termos, as pesquisadoras resolveram definir o conceito primeiramente, para logo depois traçar discussões ${ }^{(13)}$.

Compaixão ou simpatia é definida como uma resposta afetiva que consiste em sentir tristeza ou preocupação pelo outro aflito ou necessitado; envolve disposições características para a ação, especificamente ajudar. Já a empatia é definida como um sentimento de fraternidade, isto é, compreender o que uma pessoa sente, independente do que sinta. A empatia não é altruísta nem grosseira, mas propriamente, exemplifica a solidariedade implícita da raça humana. Compaixão ou simpatia é, portanto, claramente uma emoção no sentido de que é uma emoção distinta, talvez dependente das emoções dos outros, apenas na medida em que é uma resposta a elas, mas em sentido nenhum uma imitação ou reprodução delas. É essencialmente, sentir-se mal porque o outro sente mal, em combinação com um sentimento de chegar até ele ${ }^{(13)}$.

Tanto a empatia como a compaixão/simpatia são respostas afetivas e cognitivas; isto é, envolvem conceitos e formas de construir o mundo e são de grande importância para compreender as vidas emocionais das 
pessoas, é parte da capacidade natural do ser humano em sintonizar as emoções de outras pessoas e de sentir o impulso para reagir sem a necessidade de muito pensamento ${ }^{(13)}$.

No estudo em tela, percebe-se que as enfermeiras E4 e E13 realmente vivenciam o sentimento de compaixão, uma vez que esse sentimento direciona as enfermeiras a agirem, como elas mesmas expressaram "da melhor forma possível" e "se eu pudesse resolver logo a situação que ele está, resolveria". Enquanto que as demais permanecem na dimensão da empatia, ou seja, adotando posturas de solidariedade e solicitude. Contudo, cumpre assinalar que, a empatia é fator fundamental para o efetivo exercício da profissão, sobretudo, no âmbito de cuidados paliativos.

Empatia é a capacidade de interpretar os sentimentos do outro em um determinado contexto, requerendo do ser humano a disponibilidade e a habilidade de colocar-se no lugar do outro, para ver o mundo como a outra pessoa vê, podendo então genuinamente sentir-se da maneira como o outro se sente em determinada situação. Contribui para a criação de um clima interpessoal de confiança, elemento básico no relacionamento de assistência à saúde, e uma condição necessária para que esse relacionamento seja efetivo, já que a confiança e a segurança não podem ser impostas, mas construídas ${ }^{(13)}$.

Dentro desse contexto, é possível perceber que uma das enfermeiras da pesquisa utiliza o seu grau máximo de disponibilidade e empatia frente ao paciente com ferida neoplásica, quando menciona que disfarça sentir o odor pútrido da lesão, para que o paciente não perceba e não se sinta excluído.

Estudo qualitativo(10) ${ }^{(10 v e l o u}$ que os enfermeiros descrevem as feridas neoplásicas como devastadoras e que o mau odor causa náuseas e enjoos quando os mesmos entram em contato com o paciente. Destacaram também que após a realização do curativo, retirada das luvas e lavagem das mãos, ainda podiam sentir a presença do odor em suas mãos e roupas. Os enfermeiros revelaram que tentam esconder esses sentimentos quando entram em contato com os pacientes, pois acreditam que é um fator relevante e positivo no cuidado a esses pacientes.
A categoria quatro revela sentimentos de "Gratificação" das enfermeiras em relação ao cuidado de pessoas com feridas neoplásicas, sobretudo, quando proporcionam zelo, conforto, e maximização da qualidade de vida por meio de um curativo efetivo.

Estudo qualitativo(10) apontou que os enfermeiros ressaltaram sentimentos de gratificação, principalmente, quando alcançam o conforto e o alívio da dor durante o curativo. Além disso, mencionam que respeitar a pessoa diante de uma lesão incurável, promover dignidade e qualidade de vida durante do processo de morte são atitudes que dão sentido ao exercício da profissão.

Para edificar algo é necessário um determinado temperamento otimista, certa capacidade de construção. Uma relação humana pode caracterizar-se como edificante quando transforma positivamente a ambos, profissional e paciente. Uma atividade humana é edificante quando o sujeito que a desenvolve se aperfeiçoa por meio dela, e constrói a si próprio. A ação de cuidar é, nesse sentido, uma ação edificante, não somente no sentido corporal do termo, mas fundamentalmente no sentido interior. Edificar a pessoa doente e que sofre é tratar de recompor seu interior, alçar de novo sua identidade pessoal, refazer-se depois da queda e da frustração que implica o processo de adoecer ${ }^{(12)}$.

Sendo assim, cuidar de alguém, acompanhar uma pessoa vulnerável é exercer a responsabilidade ética, é preocupar-se com o outro e assumir essa preocupação como um dever moral e não unicamente como um sentimento de proximidade para com a pessoa. Precisamente, porque a ação de acompanhar ou de cuidar implica em responsabilidade, tem um caráter ético, além de antropológico, psicológico, social e espiritual. 0 processo de cuidar e de acompanhar supera os limites da técnica e contém elementos éticos. O cuidar pressupõe técnica, habilidade, mas não se reduz à técnica(12).

A categoria cinco ressalta a "Apreensão" de uma das enfermeiras ao lidar com o paciente com ferida neoplásica no momento da execução do curativo. Esse receio em realizar o curativo é comum em todos os profissionais que lidam com feridas extensas, friáveis e, sobretudo, dolorosas. 
Sendo assim, os enfermeiros precisam saber o que fazer, como obter e usar os produtos adequadamente, com vistas a minimizar episódios de dor intensa e sangramentos profusos.

Um estudo ${ }^{(10)}$ apontou que as enfermeiras descrevem o manejo clínico das feridas malignas como extremamente difícil o que levou a desenvolver sentimentos de culpa ou inadequação à profissão, uma vez que não foram capazes de gerenciar os cuidados com a ferida no que elas consideravam ser adequada.

Dada à complexidade e natureza devastadora das feridas neoplásicas, recomendase que essas lesões sejam tratadas por uma equipe multiprofissional dentro de uma abordagem voltada para a filosofia dos cuidados paliativos. Isso facilitará a prestação de cuidados de forma individualizada, o que é de importância vital para maximizar a qualidade de vida do paciente. Além disso, os enfermeiros precisam reconhecer a existência de problemas em todos os domínios da existência do paciente, ao invés de apenas enfatizar o domínio físico, que tem sido o foco da literatura contemporânea ${ }^{(8)}$.

A categoria seis expressa um sentimento de "Indolência" referido por uma enfermeira, no sentido de usar esse sentimento como norteador para uma práxis efetiva. A indolência é um tipo se sentimento que surge como um mecanismo de enfrentamento da situação hospitalar vivenciada, caracterizado como meio encontrado pelos profissionais para suportar o sofrimento que sentem, e a partir daí, exercer o trabalho da melhor maneira possível ${ }^{(14)}$.

A superação da distância espacial e da distância ética é fundamental na ação do cuidar. Não se pode cuidar de alguém à distância. Para cuidar de uma pessoa enferma, é preciso aproximar-se dela e, assim, superar a distância física. Nesse sentido, é necessário que o profissional se deixe envolver emocionalmente com o paciente, porém, é primordial que possua controle emocional sobre situações adversas durante o processo de cuidar. O envolvimento emocional é um dos aspectos vitais na relação terapêutica enfermeiro-paciente, uma vez que auxilia a ambos a serem resistentes diante das limitações que essa patologia impõe ${ }^{(15)}$.
Nesta perspectiva, um caminho possível e adequado para a humanização se constitui, acima de tudo, na presença solidária do profissional, refletida na compreensão e no olhar sensível, olhar que desperta no ser humano sentimentos de segurança e confiança. Essa presença solidária propicia o viver, o aconchego das coisas simples, mesmo diante das tensões e riscos dos momentos mutantes, imprevisíveis e plenos de significados ${ }^{(16)}$.

Para se fazer e ser o diferencial nas relações de cuidado, no ambiente hospitalar, requer-se que o profissional de saúde atue com humanidade, solidariedade, sensibilidade, além de ter postura correta e dignidade de caráter, uma vez que a sensibilidade humana é a capacidade de sentir empatia, de se deixar tocar pelas vidas, sofrimento e alegrias, esperanças e desejos de outras pessoas que têm suas particularidades e que transcendem a capacidade racional ${ }^{(16)}$.

Cuidar de pacientes com feridas neoplásicas pode ser uma experiência inexorável para os enfermeiros, tendo em vista que essas lesões são desfigurantes, sangrantes, exsudativas, exalam um odor desagradável, não cicatrizam e concorrem para mutilações. Dentro desse contexto, as necessidades dos enfermeiros que cuidam desses pacientes devem ser consideradas ${ }^{3-}$ 4-5). Assim, sugere-se que os enfermeiros que realizam curativos nesses pacientes, partilhem suas experiências profissionais em grupos de apoio, permitindo aos mesmos refletirem e compreenderem o processo emocional pelo qual estão passando.

\section{Conclusão}

Ao final deste estudo, conclui-se que os discursos apontaram sentimentos positivos e negativos, percebidos durante a realização dos curativos. Constatando que a tristeza foi mencionada como o sentimento que permeava as ações de cuidado, haja vista que as enfermeiras desenvolviam habilidades empáticas diante da dor e do sofrimento do paciente.

Espera-se que este estudo possa contribuir para construção de conhecimentos e, especialmente, para deter a atenção de gestores e profissionais sobre a necessidade de educação permanente, bem como de um espaço para 
discussão dos aspectos psicológicos e espirituais, destinado à equipe de saúde, sobretudo aos enfermeiros, uma vez que são os profissionais que estão mais próximos dos pacientes e que, geralmente, realizam os curativos, a fim de qualificar a assistência prestada.

As limitações deste estudo relacionam-se ao número de participantes e ao local do estudo, um único hospital, o que impede a generalização dos achados, porém, estes são considerados válidos, pois refletem condições semelhantes verificadas em pesquisas de maior abrangência, destacando-se a necessidade de estudos complementares que envolvam o tema. Ainda existe uma carência de estudos sobre a prática de cuidados específicos frente à pessoa com ferida neoplásica, bem como as atitudes, comportamentos e práticas de enfermeiros frente a essa condição-limite em que se encontra a pessoa com doença oncológica avançada nas instituições hospitalares, assim como no ambiente domiciliar, o que impossibilitou discussões mais aprofundadas.

\section{Referências}

1. Instituto Nacional de Câncer José Alencar Gomes da Silva (BR). Coordenação de Prevenção e Vigilância Estimativa 2016: Incidência de Câncer no Brasil/Instituto Nacional de Câncer José Alencar Gomes da Silva, Coordenação de Prevenção e Vigilância. Rio de Janeiro: INCA, 2016.

2. Ministério da Saúde (BR). Instituto Nacional do Câncer. Tratamento e controle de feridas tumorais e úlceras por pressão no câncer avançado. Série cuidados paliativos. Rio de Janeiro: INCA, 2011.

3. Gethin G, Grocott P, Probst S, Clarke E. Current practice in the management of wound odour: na internacional survey. Int J Nurs Stud. [Internet]. 2013 [acesso em 03 Jun 2015]; 51(6):865-74. Disponível em: https://www.ncbi.nlm.nih.gov/pubmed/24238490

4. Gibson S, Green J. Review of patients' experiences with fungating wounds and associated quality of life. J Wound Care [Internet]. 2013 [acesso em 03 Jun 2016]; 22(5):265-72. Disponível em:

https://www.ncbi.nlm.nih.gov/pubmed/23702724

5. Probst S, Arber A, Faithfull S. Malignant fungating wounds: the meaning of living in an unbounded body. Eur J Oncol Nurs [Internet]. 2013 [acesso em 03 Jun 2016]; 17(1):38-45. Disponível em:

https://www.ncbi.nlm.nih.gov/pubmed/22459257

6. Favero L, Pagliuca LMF, Lacerda MR. Cuidado transpessoal em enfermagem: uma análise pautada em modelo conceitual. Rev Esc Enferm USP [Internet] 2013 [acesso em 07 Ago 2016]; 47(2):500-5. Disponível em: http://dx.doi.org/10.1590/S008062342013000200032.

7. Bardin L. Análise de conteúdo. São Paulo: Edições 70; 2011.

8. Gonçalves EF, Moura SP, Souza DC, Alves RS. As percepções dos graduandos de enfermagem diante do paciente com feridas na atenção básica. Rev Rede Cuidados Saúde [Internet]. 2014 [acesso em 01 Out 2017]; 8(2):1-3. Disponível em: http://publicacoes.unigranrio.br/index.php/rcs/art icle/view/2374/1155.

9. Oliveira MCL, Firmes MPR. Sentimentos dos profissionais de enfermagem em relação ao paciente oncológico. Rev Min Enferm [Internet]. 2012 [acesso em 29 Out 2016]; 16(1):91-97. Disponível em: http://www.reme.org.br/artigo/detalhes/505.

10. Wilkes LM, Boxer E, White K. The hidden side of nursing: why caring for patients with malignant malodours wounds is so difficult. I Wound Care [Internet]. 2003 [cited Nov 01]; 12(2):76-80. Disponível em 10.12968/jowc.2003.12.2.26468.

11. Caldeira EP. Cuidados paliativos em pacientes terminais. [Monografia] Faculdade Católica Salesiana do Espírito Santo. Vitória - ES, 2013. 79 p. Disponível em: 
http://www.ucv.edu.br/fotos/files/CUIDADOS\%20 PALIATIVOS\%20EM\%20PACIENTES\%20TERMINAIS .pdf.

12. Angione L. As noções aristotélicas de substância e essência. Campinas: Editora da Unicamp; 2008.

13. Solomon RC. Fiéis às nossas emoções: o que elas realmente nos dizem. Rio de Janeiro: Civilização Brasileira; 2015.

14. Peterson AA, Carvalho EC. Comunicação terapêutica na Enfermagem: dificuldades para o cuidar de idosos com câncer. Rev Bras Enferm [Internet]. 2011 [acesso em 21 Out 2016]; 64(4):692-7. Disponível em: http://www.scielo.br/pdf/reben/v64n4/a10v64n4. pdf.

15. Alencar AR, Alencar AMPG, Menezes IRA, Kerntopf MR, Ramos AGB, Brito SMO et al. Emoção e cuidado na assistência à criança com câncer: percepções da equipe de Enfermagem. Rev Cubana Enferm [Internet]. 2014 [acesso em 30 set 2017]; 30(2):1-13. Disponível em: http://www.revenfermeria.sld.cu/index.php/enf/a rticle/view/518/88.

16. Bettinelli LA, Waskievics J, Erdmann AL. Humanização do cuidado no ambiente hospitalar. In: Pessini L, Bertachini L. Humanização e cuidados paliativos. São Paulo: Loyola; 2014. 